\title{
Atividade antioxidante in vitro de extratos de algumas algas verdes (Chlorophyta) do litoral catarinense (Brasil)
}

\author{
Melissa dos Santos Raymundo', Paulo Horta ${ }^{2}$, Roseane Fett ${ }^{1 *}$ \\ 'Departamento de Ciência e Tecnologia de Alimentos, Centro de Ciências Agrárias, Universidade Federal de Santa \\ Catarina, ${ }^{2}$ Departamento de Botânica, Centro de Ciências Biológicas, Universidade Federal de Santa Catarina
}

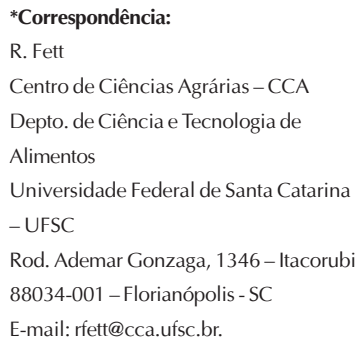

O efeito antioxidante de quatro espécies de algas marinhas do filo Chlorophyta (Codium decorticatum, Enteromorpha intestinalis, Ulva fasciata $e$ Chaetomorpha anteninna) foi avaliado através da inibição da peroxidação do ácido linoléico em emulsão. Os extratos etéreos e metanólicos, na concentração de 0,01\%, foram obtidos por extração seqüencial das biomassas secas. As espécies mais efetivas sobre a peroxidação lipídica foram Enteromorpha intestinalis $e$ Chaetomorpha anteninna, com porcentagens de inibição acima de 70\%. A habilidade dos extratos metanólicos para seqüestrar o peróxido de hidrogênio foi avaliada, obtendose valores médios para porcentagens de captura entre $1,26 \%$ e 20,01\%. Além disto, quantificaram-se os teores de clorofila a, carotenóides totais e compostos fenólicos totais nas biomassas algais. Os resultados indicam que as algas verdes estudadas são uma fonte promissora de compostos biologicamente ativos com propriedades antioxidantes.
Unitermos

- Algas marinhas

- Antioxidantes

- Compostos fenólicos

- Carotenóides

- Clorofila

\section{INTRODUÇÃO}

Apesar do alto conteúdo de ácidos graxos poliinsaturados, as algas marinhas são estáveis frente à oxidação durante seu armazenamento (Ramarathnam et al., 1995). Como qualquer organismo fotossintético, as algas encontram-se expostas à grande quantidade de luz e altas concentrações de oxigênio, combinação que origina radicais livres, assim como, outros potentes oxidantes. A ausência de danos oxidativos nos ácidos graxos poliinsaturados estruturais das membranas algais sugere que estes alimentos possuem compostos e mecanismos antioxidantes (Matsukawa et al., 1997).

As algas também são ricas em polissacarídeos e minerais, entretanto, poucas algas têm sido usadas amplamente como plantas comestíveis. O gênero Enteromorpha (Chlorophyta) possui potencial para alimentação, sendo encontrado abundantemente na costa brasileira. A constatação da atividade antioxidante poderia elevar potencialmente seu valor como alimento humano ou aditivo e expandir seu mercado consumidor. No Brasil, particularmente, as algas são pouco exploradas comercialmente, sendo quase que restrita a exploração de alguns gêneros de algas vermelhas (Oliveira, 1998).

Yan et al. (1998) trabalhando com diversas espécies algais testaram os extratos metanólicos de duas espécies de Ulva, a U. lactuca e a U. pertusa. Os resultados obtidos com o método DPPH (azo-radical 2,2-difenil-1- 
picrilidrazil) revelaram atividade de $8 \%$ para a $U$. lactuca e $15 \%$ para a $U$. pertusa frente ao radical formado. Os autores também encontraram atividade seqüestradora de radicais, em menor proporção, nos outros extratos testados. No mesmo estudo, duas espécies de Enteromorpha, a E. intestinalis e a E. prolifera, foram testadas e os extratos metanólicos apresentaram atividade seqüestradora de radicais de $15 \%$ e $7 \%$, respectivamente.

Os estudos bioquímicos enfocando algas verdes brasileiras restringem-se a componentes bioquímicos com caráter nutricional. Caldas (1986) avaliou as alterações na composição centesimal da espécie $U$. fasciata, proveniente da ilha de São Luiz (Brasil), em resposta às variações sazonais. Relatos envolvendo compostos bioativos são escassos, principalmente no que se refere a antioxidantes. Freitas e Mariglio (1986) estudaram a atividade farmacoterapêutica sobre o metabolismo cardíaco usando extratos metanólicos de duas espécies do filo Chlorophyta, obtendo resultados positivos.

O objetivo desse trabalho foi avaliar a quantidade de fenólicos totais, carotenóides totais, clorofila $a$ e o potencial antioxidante de algumas espécies de algas verdes, constatando seu valor como matéria-prima para encapsulados com características bioativas ou outros tipos de produtos, nos quais a presença de antioxidantes naturais seja efetiva, tanto para as indústrias alimentícia e farmacêutica.

\section{MATERIAL E MÉTODOS}

\section{Reagentes e solventes}

Todos os solventes orgânicos (álcool etílico, éter etílico, hexano e acetona) apresentavam grau de pureza de aproximadamente $99 \%$ ou maior. O ácido linoléico foi adquirido da Fluka e o hidroxibutilanisol (BHA) da Merck. Todos os outros reagentes comerciais foram utilizados sem purificação prévia.

\section{Coleta das amostras}

As algas foram coletadas nas Praias de Canasvieiras e Ponta das Canas, litoral norte da Ilha de Santa Catarina, nos meses de julho e agosto de 2002, sob maré baixa. Foram selecionadas, com base na maior abundância, em pontos diversificados das comunidades algais, para garantir variabilidade amostral. As espécies foram identificadas segundo os métodos convencionais no Laboratório de Algas Marinhas da Universidade Federal de Santa Catarina e estão depositadas no Herbário da referida instituição. Os testes foram realizados com quatro espécies de Chlorophyta: Ulva fasciata Delile, Codium decorticatum (Woodw.) M. Howe, Enteromorpha intestinalis e Chaetomorpha anteninna (Bory) Kütz.

\section{Preparo das amostras}

As amostras foram limpas, lavadas com água potável para retirada do sal e, em seguida, enxaguadas com água destilada. Posteriormente, foram secas em estufa, da marca FR Santer, com circulação forçada de ar a 35,0 \pm $0,5^{\circ} \mathrm{C}$ até secagem completa (aproximadamente 24 horas). Após secagem, as amostras foram armazenadas em freezer a $-18,0 \pm 0,5^{\circ} \mathrm{C}$, sob atmosfera de nitrogênio, para posterior análise.

\section{Obtenção dos extratos}

Os extratos foram obtidos por extração seqüencial das amostras. Pesaram-se 5,0 g da biomassa seca, em balança da marca Metler Toledo modelo AB204-S, triturou-se em processador doméstico da marca Walita, estando a granulometria das partículas compreendida entre 1,75 e 3,00 mm. A extração seqüencial teve como solventes éter etílico seguido de metanol, sob agitação mecânica ao abrigo total da luz, durante período de duas horas. Os extratos foram filtrados em papel Whatman $\mathrm{n}^{\circ} .1$ e concentrados sob atmosfera de nitrogênio. A determinação do peso seco foi realizada por gravimetria, tomando-se uma alíquota de $5 \mathrm{~mL}$ em cadinho de porcelana, previamente tarado, seguido de secagem em estufa a $105,0 \pm 0,5^{\circ} \mathrm{C}$ até peso constante (AOAC, 1990).

\section{Avaliação da atividade antioxidante pelo método do Tiocianato Férrico}

A atividade antioxidante dos extratos etéreo e metanólico foi avaliada de acordo com a metodologia descrita por Mitsuda et al. (1967) apud Kikizaki e Nakatani (1993), com modificações. Mistura contendo $1 \mathrm{~mL}$ do extrato algal, 1,1 mL de ácido linoléico 2,51\% (p/v) em etanol $(99,0 \% \mathrm{v} / \mathrm{v}), 2 \mathrm{~mL}$ de tampão fosfato $0,05 \mathrm{M}(\mathrm{pH}$ $7,0)$ e $0,9 \mathrm{~mL}$ de água destilada foi colocada num frasco de vidro âmbar com tampa rosqueável e estocada em estufa com circulação de ar forçada, a $50,0 \pm 0,5^{\circ} \mathrm{C}$. Para $0,1 \mathrm{~mL}$ desta solução foram adicionados $5 \mathrm{~mL}$ de etanol 75\% (v/ v), $0,1 \mathrm{~mL}$ de tiocianato de amônio $30 \%$ (p/v) e $0,1 \mathrm{~mL}$ de cloreto ferroso $0,02 \mathrm{M}$. Após, exatamente, 3 minutos de reação à temperatura ambiente $\left(25,0 \pm 0,5^{\circ} \mathrm{C}\right)$, foi realizada leitura da absorbância a $500 \mathrm{~nm}$, em espectrofotômetro Hewlet Pakard modelo 8452A UV-VISIVEL, o que se repetiu a cada 24 horas, até que a cor púrpura do 
controle alcançasse um valor máximo. A concentração dos extratos e do antioxidante sintético hidroxibutilanisol, BHA, foi de $0,01 \%(\mathrm{p} / \mathrm{v})$. A porcentagem de inibição na oxidação lipídica foi calculada de acordo com a expressão algébrica:

\% inibição $=\{[a b s$. média final do controle - abs. média final da amostra]/abs. média final do controle? $x 100$.

\section{Avaliação do poder seqüestrador do peróxido de hidrogênio dos extratos metanólicos}

A habilidade dos extratos em seqüestrar peróxido de hidrogênio foi determinada de acordo com o método de Ruch et al. (1989) apud Yen e Chen (1995). Uma solução (4 mM) de peróxido de hidrogênio foi preparada em tampão fosfato (pH 7,4). A concentração de peróxido de hidrogênio foi determinada espectrofotometricamente no comprimento de onda de $230 \mathrm{~nm}$, usando absortividade molar de $81^{-1} \mathrm{~cm}^{-1}$ (Beers e Sizer, apud Yen e Chen, 1995). Ao extrato (10-400 $\mathrm{mL}$, em $4 \mathrm{~mL}$ de água destilada) adicionouse solução de peróxido de hidrogênio $(0,6 \mathrm{~mL})$. Após 10 minutos de reação, à temperatura ambiente $\left(25,0 \pm 0,5^{\circ} \mathrm{C}\right.$, realizou-se leitura em espectrofotômetro, em comprimento de onda de $230 \mathrm{~nm}$, contra solução branco contendo o extrato em tampão sem peróxido de hidrogênio.

\section{Determinação dos compostos fenólicos totais}

O conteúdo de compostos fenólicos totais foi determinado, usando protocolo segundo Budini et al. (1980) para extração e protocolo similar ao de Amerine e Ough (1976) para quantificação. Pesou-se 0,5 g da biomassa seca e triturada e adicionou-se solução de $\mathrm{HCl} 2 \mathrm{M}$ numa proporção 1:10 (p/v), aquecendo-se durante 30 minutos em banho de água a $\left(95,0 \pm 0,5^{\circ} \mathrm{C}\right)$. A mistura foi, então, filtrada em papel Whatman $\mathrm{n}^{\circ} .1$ para um balão volumétrico de $100 \mathrm{~mL}$. Completou-se o volume. Exatamente 1,0 mL do extrato foi transferido para balão volumétrico de $100 \mathrm{~mL}$, seguido pela adição de $60 \mathrm{~mL}$ de água destilada e $5 \mathrm{~mL}$ do reativo de Folin-Ciocalteu. Após um minuto, adicionaram-se $15 \mathrm{~mL}$ de solução de carbonato sódico a $20 \%$, completou-se o volume e deixou-se em repouso durante duas horas sob abrigo da luz a $24,0 \pm 0,5^{\circ} \mathrm{C}$. Determinouse a absorbância a 756 nm, em espectrofotômetro. A curva de calibração foi construída com ácido gálico, $\mathrm{R}^{2}=0,99$, numa faixa de concentração de $(0,5-5,0) \mathrm{mg} / \mathrm{mL}$ de ácido gálico.

\section{Determinação das clorofilas a e b}

A extração da clorofila foi realizada, utilizando-se
1,0 g da biomassa, fresca, em $50 \mathrm{~mL}$ de acetona, sob maceração durante 24 horas a $5,0 \pm 0,5^{\circ} \mathrm{C}$, sob abrigo da luz, para evitar danos fotoxidativos. Em seguida, os extratos foram centrifugados a $2000 \mathrm{rpm}$, em centrifugador da marca Fanem, modelo 204, durante 5 minutos e o sobrenadante analisado em espectrofotômetro em comprimento de onda de $662 \mathrm{~nm}$ para clorofila $a$ e $646 \mathrm{~nm}$ para clorofila $b$. Os valores de coeficientes de extinção $\mathrm{E}_{\mathrm{cm}}{ }^{1 \%}$, para clorofilas $a$ e $b$ em acetona, foram citados em Jones, Whyte e Gibbs (1962).

\section{Determinação dos pigmentos carotenóides totais}

O procedimento de extração dos pigmentos carotenóides seguiu protocolo segundo Kurilich e Juvik (1999). A absorbância foi lida em espectrofotômetro no comprimento de onda de máxima absorção. Cada carotenóide possui seu ponto de máxima absorção em um dado solvente, que pode ser obtido em tabelas para identificação de carotenóides (Mosquera, 1997; Davies, 1976). A concentração foi expressa em termos do pigmento carotenóide majoritário, com base em dados cromatográficos obtidos no laboratório (valor de Rf para cromatografia em camada delgada e espectro de absorção de luz). Estes dados foram comparados com valores referenciais encontrados em literatura para carotenóides (Mosquera, 1997; Davies, 1976). Os valores dos coeficientes de extinção $\mathrm{E}_{\mathrm{cm}}{ }^{1 \%} \mathrm{em}$ etanol foram consultados nas tabelas de identificação de carotenóides encontradas em Davies (1976).

\section{Análise estatística}

A análise estatística foi realizada com auxílio do programa Statistica, versão 5.0 (1986-1996). Aplicou-se análise de variância (ANOVA), sendo que as diferenças significativas foram determinadas pelo teste de Tukey. Diferenças entre médias a um nível de $5 \%(\mathrm{p}<0,05)$ foram consideradas significativas. Todas as análises foram realizadas em triplicata.

\section{RESULTADOS E DISCUSSÃO}

Os valores médios de absorbância referentes à peroxidação do ácido linoléico, determinados pelo método de tiocianato férrico, a $50{ }^{\circ} \mathrm{C}$, após a adição dos extratos etéreos são apresentados na Figura 1. Os valores para os extratos metanólicos estão apresentados na Figura 2. Nos estágios iniciais da autoxidação do ácido linoléico, os extratos etéreos das espécies $U$. fasciata e $E$. intestinalis apresentaram efeito pró-oxidante em relação ao controle (Figuras 1 e 2). O mesmo efeito pode ser observado para 
os extratos metanólicos das espécies algais U. fasciata e C. decorticatum em relação ao controle na Figura 2.

A atividade antioxidante dos extratos algais foi comparada com a atividade do antioxidante comercial BHA. Observou-se que todos os extratos etéreos proporciona- ram inibição da peroxidação lipídica menor que 50\%. O valor médio máximo de $39,43 \%$ foi da espécie algal $C$. anteninna, enquanto que entre os extratos metanólicos, os mais efetivos foram das espécies $E$. intestinalis e $C$. anteninna. Existem dados na literatura que correlacionam

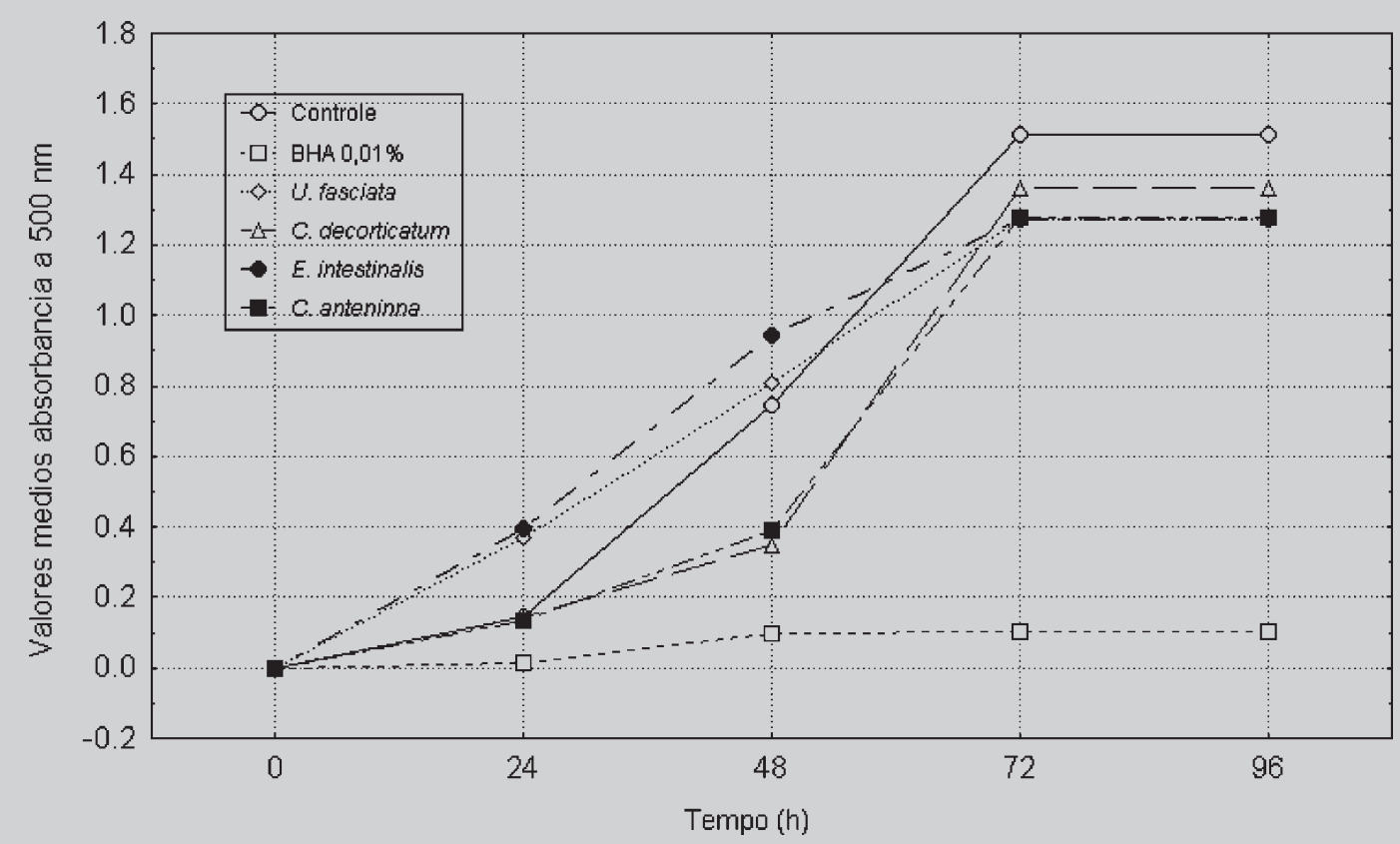

FIGURA 1 - Valores médios de absorbância das amostras contendo os extratos etéreos das algas marinhas $(0,01 \%)$ obtidos no teste do tiocianato férrico nos tempos de $0,24,48,72$ e 96 horas.

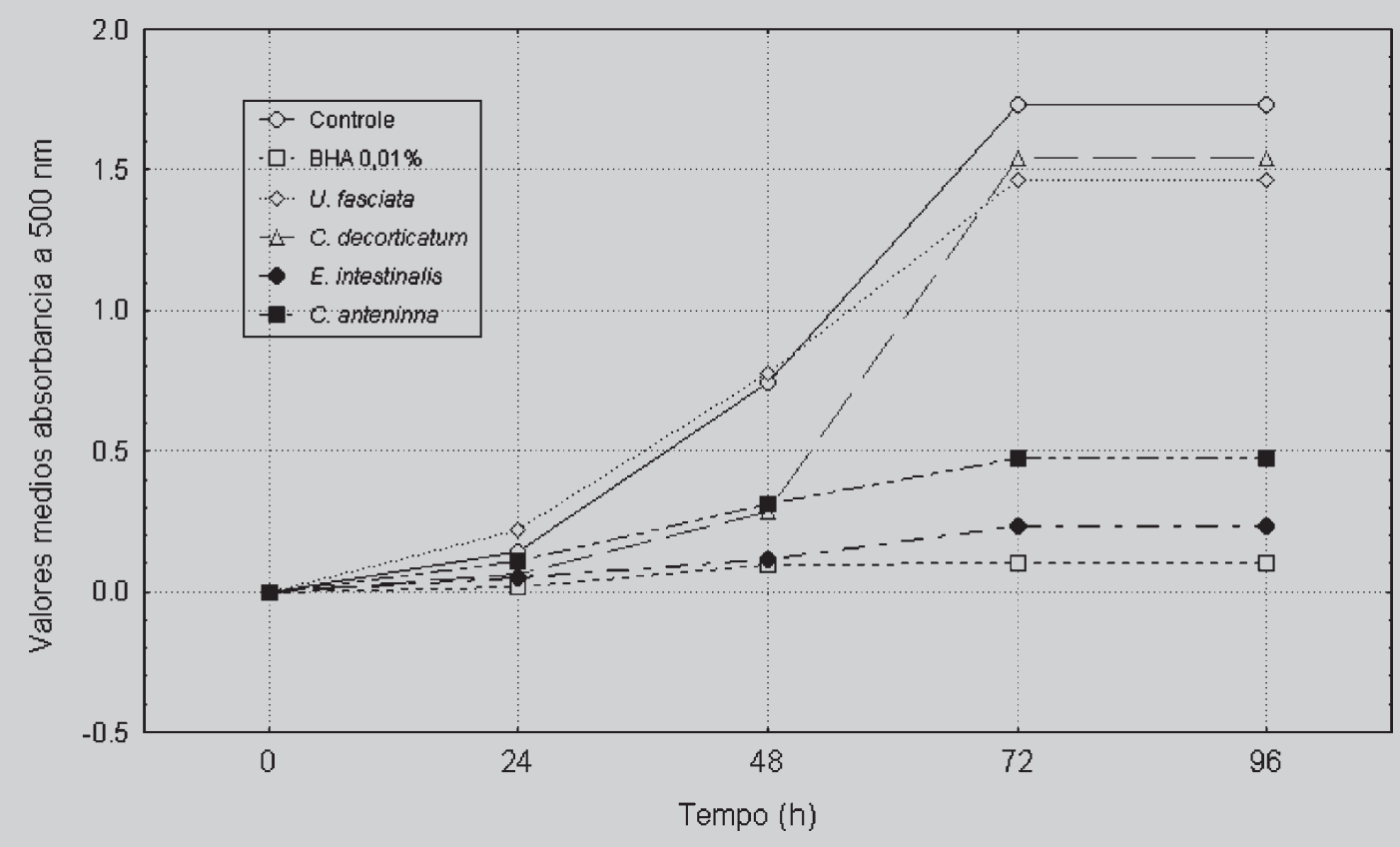

FIGURA 2 - Valores médios de absorbância das amostras contendo os extratos metanólicos das algas marinhas $(0,01 \%)$ obtidos no teste do tiocianato férrico nos tempos de $0,24,48,72$ e 96 horas. 
atividade antioxidante de plantas com características antiinflamatórias das mesmas (Recio et al., 1995; Sadique et al., 1987). Assim sendo, plantas contendo atividade antioxidante, a exemplo das algas deste estudo, poderiam ser utilizadas na terapia de processos antiinflamatórios. $\mathrm{Na}$ concentração testada, nenhum extrato superou a eficiência do antioxidante sintético de $92,45 \%$ (Figura 3). Em geral, os antioxidantes naturais não são tão eficientes na desativação de radicais livres, em testes in vitro, quanto os sintéticos, como o BHA. Isto reafirma a necessidade da constante busca por antioxidantes naturais mais efetivos, especialmente para fins industriais.

A efetividade antioxidante de fontes naturais foi relacionada por diversos autores aos compostos fenólicos, que ocorrem naturalmente em plantas terrestres e aquáticas (Hayase, Kato, 1984). Seriam esses compostos os principais responsáveis pela atividade antioxidante de plantas, desempenhando papel fundamental na inibição da autoxidação em óleos (Ramarathnam et al., 1986). A ocorrência natural de fenóis substituídos e polifenóis em algas vem sendo cientificamente divulgada e ampliada ao longo dos anos (Pedersen, 1978). Embora essa classe de compostos inclua antioxidantes efetivos (Denisov, 1987), pouco é conhecido sobre a atividade antioxidante de extratos algais. Das 21 espécies algais marinhas estudadas por Fujimoto e Kaneda (1980), cerca de 60\% apresentaram atividade antioxidante em algum grau. Na Figura 3 estão expressos os valores médios dos compostos fenólicos totais encontrados para as espécies testadas, valores obtidos através do método espectrofotométrico de Folin-Ciocalteu (Amerine, Ough, 1976), além das porcentagens de inibição da peroxidação do ácido linoléico.

A maior porcentagem de inibição $(75,75 \%)$ foi obtida pelo extrato metanólico da espécie $E$. intestinalis, cuja biomassa continha um dos maiores valores de fenólicos totais $(610,31 \mathrm{mg} / 100 \mathrm{~g})$. Apesar da biomassa da espécie $U$. fasciata apresentar quantidade de compostos fenólicos semelhante estatisticamente $(635,53 \mathrm{mg} / 100 \mathrm{~g})$ a da $E$. intestinalis, a efetividade antioxidante entre os extratos metanólicos das duas espécies apresentou diferenças significativas $(p<0,05)$. Este resultado sugere distinções na composição química entres os compostos fenólicos de tais algas, diferenças na solubilidade desses compostos pelo solvente utilizado ou, finalmente, o envolvimento na atividade antioxidante de outros compostos antioxidantes, presentes nos extratos algais, além dos fenólicos, a exemplo de carotenóides e clorofilas. Em acordo com a hipótese anterior, Nakamura et al. (1996) isolaram em espécies do gênero Enteromorpha um antioxidante, relativamente hidrofóbico, identificado como feofitina $a$, que se constitui em uma clorofila sem magnésio. Na Figura 3 verificam-se, também, as diferentes eficiências antioxidativas entre os extratos etéreos e metanólicos, sendo o último mais efetivo. Yan, Nagata e Fan (1998) avaliaram a atividade

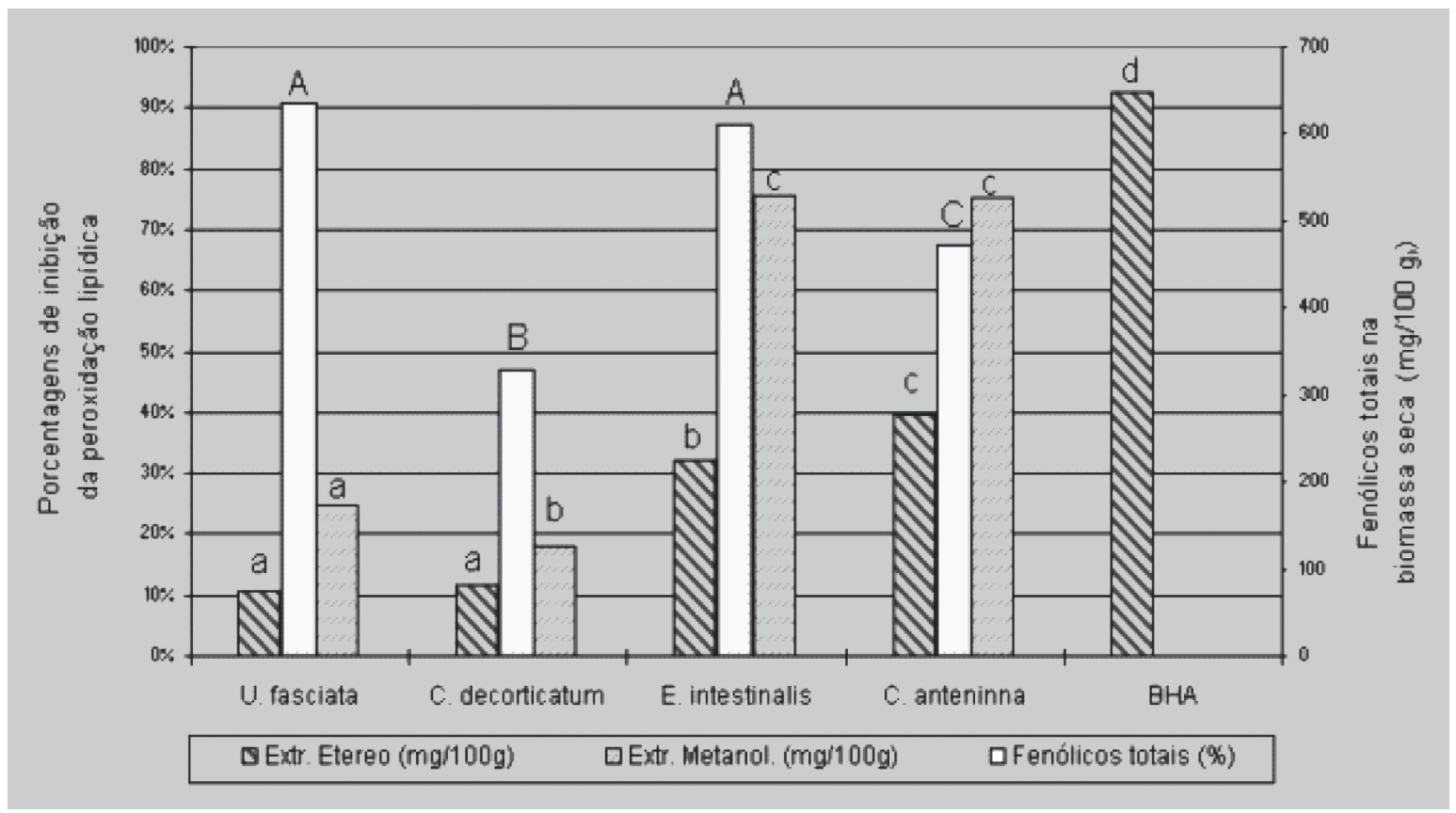

FIGURA 3 - Valores médios para porcentagem de inibição da peroxidação lipídica do ácido linoléico proporcionada pela adição dos extratos etéreos e metanólicos, juntamente com os valores médios para teores de fenólicos totais das biomassas secas. Os valores seguidos por letras iguais não diferem estatisticamente $(p<0,05)$. 
antioxidante de 27 espécies de algas pelo método DPPH (2,2-difenil-1-picrilidrazil) utilizando quatro solventes orgânicos por extração seqüencial. Os autores observaram grandes diferenças na atividade seqüestradora de radicais entre as diferentes espécies de algas. Nesse estudo e em outros (Anggadiredja et al., 1997), o extrato metanólico geralmente apresenta os maiores valores de atividade antioxidante em muitas espécies algais, sugerindo que o metanol seja um solvente mais efetivo durante o preparo de extratos algais, especialmente se o estudo visa à investigação da atividade antioxidante destes.

Os extratos metanólicos algais foram capazes de seqüestrar o peróxido de hidrogênio, mas o efeito foi bastante reduzido variando entre 1,26 e $20,01 \%$. Os extratos mais efetivos foram aqueles das espécies $C$. anteninna $(1,26 \%$ a $20,01 \%)$ e $E$. intestinalis $(1,18 \%$ a $13,16 \%)$ para os volumes testados $(10 \mu \mathrm{L}-400 \mu \mathrm{L})$. Elevada habilidade em seqüestrar o peróxido de hidrogênio está relacionada à presença de antioxidantes, no extrato, capazes de reagir com radicais livres. Essa relação pode ser observada na Figura 4. A regressão linear sugere aumento do poder seqüestrador com um aumento da atividade antioxidante $\left(\mathrm{R}^{2}=0,7648\right)$.

O filo Chlorophyta possui clorofilas $a$ e $b$, xantófilas (principalmente, a luteína) e carotenos (principalmente, o b-caroteno). Carotenóides e clorofila $a$ são conhecidos por atuar como antioxidantes em testes in vitro (Naguib, 2000; Cahyana et al., 1993). Na Figura 5 são apresentados os valores médios de tais compostos, obtidos por métodos espectrofotométricos para as biomassas algais. Os valores para clorofila $a$ variaram entre 151,48 e $411,51 \mathrm{mg} / \mathrm{kg}$, sendo o maior da espécie $C$. anteninna e o menor da espécie $C$. decorticatum. Os valores médios para o conteúdo de carotenóides totais variaram entre 72,27 e $129,04 \mathrm{mg} / \mathrm{kg}$, sendo o maior teor da espécie $E$ intestinalis e o menor da espécie $U$. fasciata,. Os extratos algais constituem mistura de diversos compostos com potencial antioxidante. Le Tutour et al. (1998), estudando a habilidade de cinco espécies algais em seqüestrar radicais peroxila em um sistema modelo, observaram que a atividade antioxidante dos cinco extratos examinados não se deveu, aparentemente, apenas aos seus conteúdos de tocoferol, muitos outros compostos lipossolúveis, geralmente encontrados em algas (Ito e Hori, 1989) e identificados em extratos algais, como carotenóides e clorofila, podem atuar como antioxidantes.

Endo, Usuki e Kaneda (1985) relataram que a clorofila $a$ exibe alguma atividade antioxidante no escuro, destacando a importância do anel porfirina como estrutura essencial para esse efeito. De modo geral, derivados da porfirina desempenham alguma atividade antioxidante (Cahyana et al., 1993). Le Tutour, Brunel e Quemeneur (1996) estudaram o efeito sinérgico da adição de clorofila $a$ à vitamina $E$ na preservação do linoleato de metila em um sistema modelo. A clorofila atuou sinergicamente, proporcionando aumento de $24 \%$ no efeito inibidor, numa concentração de $0,1 \mathrm{mmol} \mathrm{L}^{-1}$. A luteína, principal carotenóide da classe Chlorophyta, possui atividade, assim como o $\beta$ -

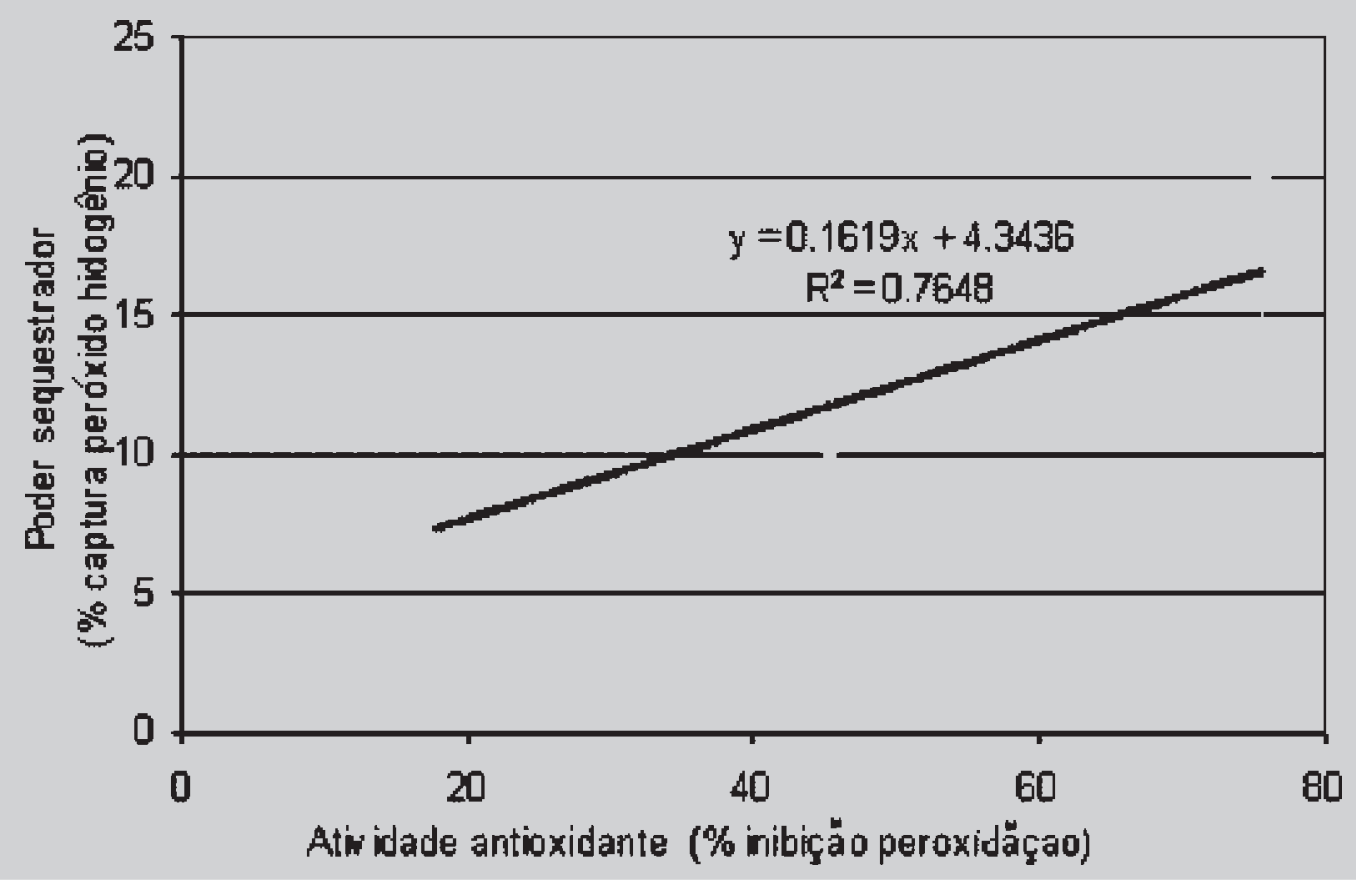

FIGURA 4 - Regressão da atividade antioxidante versus o poder seqüestrador dos extratos metanólicos testados. 


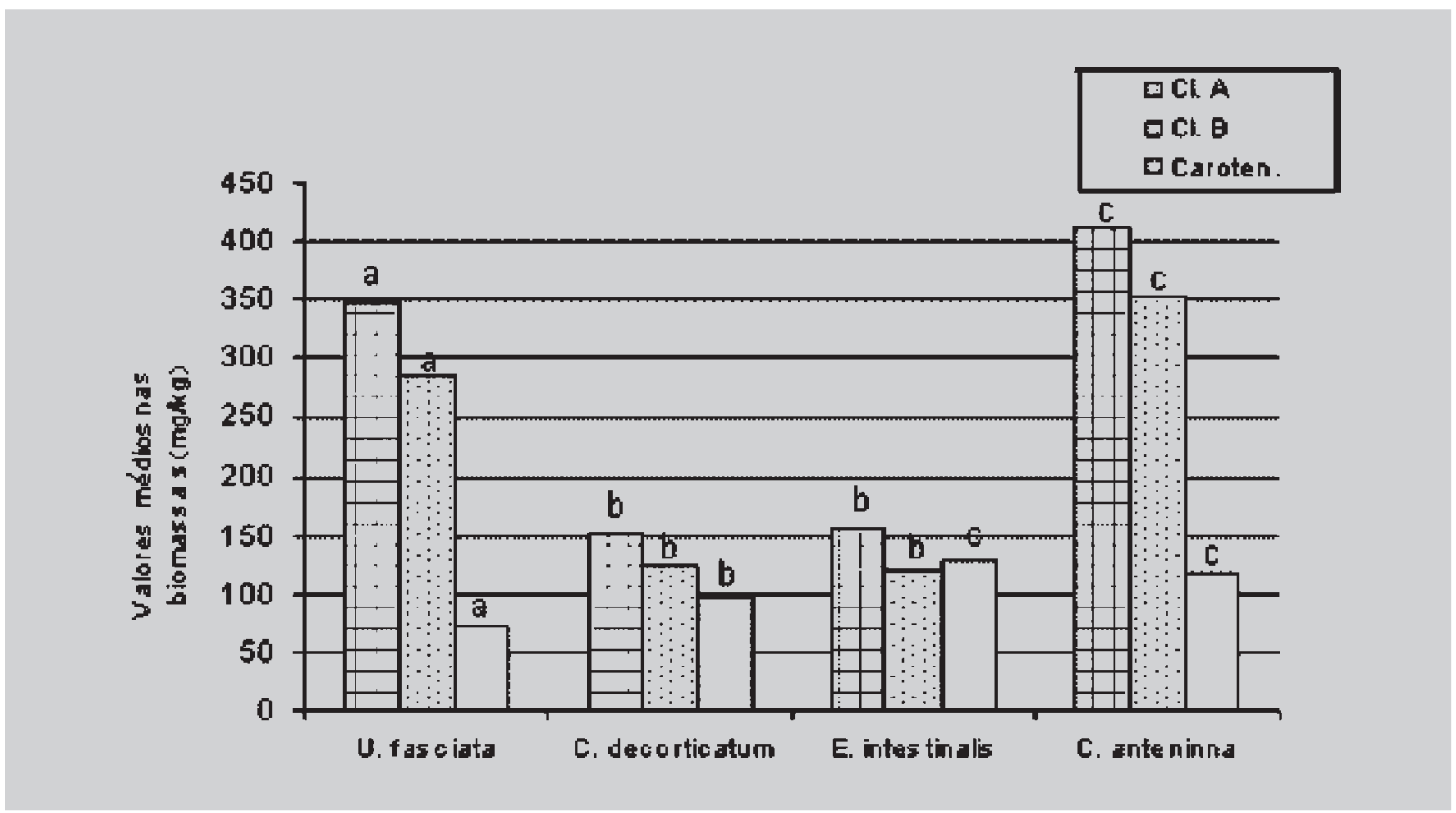

FIGURA 5 - Valores médios dos conteúdos de pigmentos clorofílicos e carotenóides encontrados nas biomassas. Os carotenóides totais foram expressos em luteína. As colunas de mesma cor cuja letra no topo forem iguais não diferem significativamente $(\mathrm{p}<0,05)$.

caroteno (Burton e Ingold, 1984; Mortensen et al., 1997). Dados na literatura relatam que a alga verde Enteromorpha spp. contém quantidades de $\beta$-caroteno maiores do que a de vegetais amarelo-esverdeados. As quantidades variam de 22 a $25 \mathrm{mg} / 100 \mathrm{~g}$ (Ito e Hori, 1989). O $\beta$-caroteno reage com peróxidos lipídicos (Tsuchihashi et al., 1995). Mortensen et al. (1997) avaliaram os mecanismos e taxas de reação da luteína e outros carotenóides com radicais gerados de radiólise de pulso e concluíram que o mecanismo de taxa de captura de um determinado carotenóide é fortemente dependente da natureza das espécies oxidantes (radicais) e da estrutura do carotenóide.

\section{CONCLUSÕES}

As algas verdes possuem diversos compostos de grande interesse para as indústrias de alimentos, cosméticos e farmacêutica. Compostos como carotenóides, clorofilas e fenólicos foram abundantemente encontrados nas espécies analisadas. Observou-se melhor atividade antioxidante nos extratos metanólicos em relação aos extratos etéreos. Embora os valores para porcentagem de inibição da peroxidação lipídica dos extratos metanólicos, principalmente em duas espécies, E. intestinalis e $C$. anteninna, tenham sido superiores a $70 \%$, nenhum dos extratos, na concentração testada, apresentou maior eficiência do que o antioxidante sintético.

\begin{abstract}
Antioxidant in vitro activity of extracts of some green seaweed (Chlorophyta) from southern Brazilian coast

The antioxidant activity of four species of green seaweeds of the phylo Chlorophyta (Codium decorticatum, Enteromorpha intestinalis, Ulva fasciata and Chaetomorpha anteninna) collected at the seacoast of the State of Santa Catarina, Brazil, was evaluated by means of the inhibition of peroxidation of linoleic acid converted into emulsion. Both ethereal and methanolic extracts were obtained from dried biomasses by sequential extraction procedures in concentrations of $0.01 \%$. The most efficient species towards lipid peroxidation were E. intestinalis and $C$. anteninna with inhibition yields above $70 \%$. The capacity of methanolic extracts to quench hydrogen peroxide was also estimated. Mean values varied from 1.26 to $20.01 \%$. Chlorophylls a, total carotenoids and phenolic compounds were also quantified in the biomasses. Results indicated that studied green seaweeds are a very promising source of biologically active compounds with antioxidant properties.
\end{abstract}

UNITERMS: Sea algae. Antioxidants. Phenolic compounds. Carotenoids. Chlorophylls. 


\section{REFERÊNCIAS BIBLIOGRÁFICAS}

AMERINE, M. A.; OUGH, C. S. Análisis de vinos y mostos. Zaragoza: Acribia, 1976. 158p.

ANGGADIREDJA, J.; ANDYANI, R.; HAYATI; MUAWANAH. Antioxidant activity of Sargassum polycystum (Phaeophyta) and Laurência obtusa (Rhodophyta) from Seribu Islands. J. Appl. Phycol., v.9, p.477-479, 1997.

ASSOCIATION OF OFFICIAL ANALYTICAL CHEMISTRY. Official methods of analysis of the Association of Official Analytical Chemistry. 16. ed. Arlington, 1990. cap.6, p.6.

BUDINI, R.; TONELLI, D.; GIROTTI, S. Analysis of total phenols using the prussian blue method. J. Agric. Food Chem., v.28, p.1236-1238, 1980.

BURTON, G. W.; INGOLD, K. U. $\beta$-Carotene: an unusual type of lipid antioxidant. Science, v.224, p.569-573, 1984.

CAHYANA, A. H.; SHUTO, Y.; KINOSHITA, Y. Antioxidative activity of porphyrin derivatives. Biosci. Biotech. Biochem., v.57, n.4, p.680-681, 1993.

CALDAS, P. Seaweeds: science and technology for sustainable industry. In: INTERNATIONAL SEAWEED SYMPOSIUM , 12., 1986. Programme and Book Abstracts. Santa Bárbara: Science Press, 1986. p.437.

DAVIES, B. H. Carotenoids. In: GOODWIN, T. W., ed. Chemistry and biochemistry of plant pigments. London: Academic Press, 1976. v.2, 38p.

DENISOV, E. T.; KHUNDYAKOV, I. V. Título do artigo? Chem. Rev., v.87, p.1313, 1987.

ENDO, Y.; USUKI, R.; KANEDA, T. Antioxidant effects of chlorophyll and pheophytin on the autoxidation of oils in the dark. II. The mechanism of antioxidative action of chlorophyll. J. Am. Oil Chem. Soc., v.62, n.9, 1985.

FREITAS; MARIGLIO. Pharmacological activity of some marine algae from brazilian coast. In: INTERNATIONAL SEAWEED SYMPOSIUM, 12 ., 1986. Programme and Book Abstracts. Santa Bárbara: Science Press, 1986. p.501.
FUJIMOTO, K.; KANEDA, T. Screening test for antioxygenic compounds from marine algae and fractionation from Eisenia bicyclis and Undaria pinnatifida. Bull. Japan Soc. Sci. Fish., v.46, p.1125$1130,1980$.

HAYASE, F.; KATO, H. Antioxidative components of sweet potates. J. Nutr. Sci. Vitaminol., v.30, p.37-46, 1984.

ITO, K.; HORI, K. Seaweed: chemical composition and potential food uses. Food Rev. Intern., v.5, n.1, p.101$144,1989$.

JONES, I. D.; WHITE, R. C.; GIBBS, E. Some pigments changes in cucumbers during brining and brine storage. Food Technol., v.55, p.1548-1550,1962.

KIKUZAKI, H.; NAKATANI, N. Antioxidant effects of some ginger constituents. J. Food Sci., v.58, p.14071410, 1993.

KURILICH, A. C.; JUVIK, J. A. Quantification of carotenoids and tocopherol antioxidants in zea mays. $J$. Agric. Food Chem., v.47, p.1948-1955, 1999.

LE TUTOUR, B.; BRUNEL, C.; QUEMENEUR, F. Effect de synergie de la chlorophylle a sur les proprietés antioxydantes de la vitamine E. New J. Chem., v.20, p.707$721,1996$.

LE TUTOUR, B.; BENSLIMANE, F.; GOULEAU, M.P.; GOUYGOU, J.P.; SAADAN B.; QUEMENEUR, F. Antioxidant and pro-oxidant activities of the brown algae, Laminaria digitata, Himanthalia elongata, Fucus vesiculosus, Fucus serratus and Ascophyllum nodosum. J. Appl. Phycol., v.10, p.121-129, 1998.

MATSUKAWA, R.; DUBINSKY, Z.; KISHIMOTO, E.; MASAKKI, K.; MASUDA, Y.; TAKEUCHI, T. A comparison of screening methods for antioxidant activity in seaweeds. J. Appl. Phycol., v.9, p.29-35, 1997.

MORTENSEN, A.; SKIBSTED, L. H.; SAMPSON, J.; RICE-EVANS, C.; EVERETT, S. A. Comparative mechanisms and rates of free radical scavenging by carotenoid antioxidants. FEBS Lett., v.48, p.91-97, 1997.

MOSQUERA, M. I. M, ed. Clorofilas y carotenoides en tecnología de alimentos. Sevilla: Universidad de Sevilla, 1997.p.111-154. 
NAGUIB, Y. M. A. Antioxidant activities of astaxanthin and related carotenoids. J. Agric. Food Chem., v.48, p.11501154, 2000.

NAKAMURA, T.; NAGAYAMA, K.; UCHIDA, K.; TANAKA, R. Antioxidant activity of phlotannins from the brown alga Eisenia bicyclis. Fish. Sci., v.62, p.923-926, 1996.

OLIVEIRA, E. C. The seaweed resources of Brazil. In: CRITCHLEY, A.T.; OHNO, M., eds. Seaweed resources of the world. Yokosuka: Japan International Cooperation Agency, 1998. p.367-371

PEDERSEN, M. Actividad antioxidante y acidos fenólicos del alga marina. Phytochem., v.17, p.291, 1978.

RAMARATHNAM, N.; OSAWA, T.; NAMIKI, M.; TASHIRO, T. Studies on the relaionship between antioxidative activity of rice hull and germination ability of rice seeds. J. Sci. Food Agric., v.37, p.719-726, 1986.

RAMARATHNAM, N.; OSAWA, T.; OCHI, H.; KAWAKISHI, S. The contribution of plant food antioxidants to human health. Trends Food Sci. Technol., v.6,p.75-82, 1995.
RECIO, M. C.; GINER, R. M.; MÁÑEZ, S. Screening of tropical medicinal plants for antinflammatory activity. Phytoth. Res., v.9, p.571-574, 1995.

SADIQUE, J.; CHANDRA, T.; THENMOZHI, T. Biochemicals modes of action of Cassia occidentalis and Cardiospermum halicatum in inflamantion. $J$. Ethnopharmacol., v.19, p.213-219, 1987.

TSUCHIHASHI, H.; HIGOSHI, M.; IWATSUKI, M.; NIKI, E. Action of b-caroteno as an antioxidant against lipid peroxidation. Arch. Biochem. Biophys., v.323, p.137147, 1995.

YAN, X.; NAGATA, T.; FAN, X. Antioxidative activities in same common seaweeds. Plant Foods Hum. Nutr., v.52, p.253-262, 1998.

YEN, G. C.; CHEN, H. Y. Antioxidant activity of various tea extracts in relation to their antimutagenicity. J. Agric. Food Chem., v.43, p.27-32, 1995.

Recebido para publicação em 23 de julho de 2003. Aceito para publicação em 20 de agosto de 2004. 